\title{
A Note on Economic Order Quantity Model
}

\author{
N. Tungalag, M. Erdenebat, R. Enkhbat* \\ National University of Mongolia, Ulaanbaatar, Mongolia \\ Email: *renkhbat46@yahoo.com
}

How to cite this paper: Tungalag, N., Erdenebat, M. and Enkhbat, R. (2017) A Note on Economic Order Quantity Model. iBusiness, 9, 74-79.

https://doi.org/10.4236/ib.2017.94006

Received: October 24, 2017

Accepted: December 3, 2017

Published: December 6, 2017

Copyright $(\odot 2017$ by authors and Scientific Research Publishing Inc. This work is licensed under the Creative Commons Attribution International License (CC BY 4.0).

http://creativecommons.org/licenses/by/4.0/

\begin{abstract}
Economic Order Quantity ( $E O Q$ ) model has been extended. We formulate $E O Q$ model as a calculus of variations. This new extended problem is a simple optimal control problem with an unknown initial state. By solving this problem we generalize $E O Q$ formula [1].
\end{abstract}

\section{Keywords \\ $E O Q$, Cost Minimization, Inventory Management}

\section{Introduction}

The economic order quantity (EOQ) formula plays an important role in inventory management. EOQ model has had on a century of researchers and practitioners in the fields of operations management and operations research. EOQ model appeared in Harris (1913) describes a very simple deterministic inventory planning model with a tradeoff between fixed ordering cost and inventory carrying cost [1]. EOQ lays the foundation for all kinds of extensions and real world management applications [2] [3] [4] [5]. Both the deterministic and the stochastic EOQ models were developed in [1] [5] [6] [7] [8]. The Economic Order Quantity $(E O Q)$ is the number of units that a company should add to inventory with each order to minimize the total costs of inventory-such as holding costs, and shortage costs. The $E O Q$ is used as part of a continuous review inventory system in which the level of inventory monitored at all times and a fixed quantity is ordered each time the inventory level reaches a specific reorder point. The EOQ provides a model for calculating the appropriate reorder point and the optimal reorder quantity to ensure the instantaneous replenishment of inventory with no shortages. It can be a valuable tool for small business owners who need to make decisions about how much inventory to keep on hand, how many items to order each time, and how often to reorder to incur the lowest possible costs. 
The EOQ model assumes that demand is constant, and that inventory is depleted at a fixed rate until it reaches zero. At that point, a specific number of items arrive to return the inventory to its beginning level. Since the model assumes instantaneous replenishment, there are no inventory shortages or associated costs. Therefore, the cost of inventory under the EOQ model involves a tradeoff between inventory holding costs (the cost of shortage, as well the cost of tying up capital in inventory rather than investing or using it other purposes) and order costs (any fees associated with placing orders, such as delivery charges). Ordering a large amount at one time will increase a small business's holding costs, while making more frequent orders of fewer items will reduce holding costs but increase order costs. The $E O Q$ model finds the quantity that minimizes the sum of these costs.

The $E O Q$ model computed by the following formula $E O Q=\sqrt{\frac{2 D c}{c_{h}}}$, where $D$ is the demand per time unit, $c$ is the ordering cost, $c_{h}$ is the holding cost a per unit and time unit.

Research on the $E O Q$ can be primarily classified into three areas of interest:

1) The performance of the $E O Q$ against other lot-sizing rules: Lot size refers to the quantity of an item ordered for delivery on a specific date or manufactured in a single production run. Choi et al. [9] examined the $E O Q$ versus eight other rules in multi-echelon MRP systems using FORTRAN, with the EOQ performing in the lower third. Evan L. Porteus [10] has introduced a model that shows a significant relationship between quality and lot size. Melnyk and Piper [11] examined the effects of lead time errors on different lot sizing rules.

2) Extensions of the $E O Q$ model: $E O Q$ extensions include an application to retail cycle stock inventories [12], the addition of cost changes under a finite or infinite time horizon [13], the inclusion of storage size considerations [6], and the addition of damage costs [5] [14] provided an exhaustive summary of the research on $E O Q$ models that handle partial backordering, and some even more current models with partial or full backordering include those by [7] [15] [16] and [17].

3) The role of the EOQ in logistics: Research that addressed the use of $E O Q$ models in transportation and logistics first appeared in the 1980s. Eppen [18] was the first to discuss the "impact of inventories" on locations by exploiting risk pooling effects. Tanchoco et al. [19] considered the impact of material handling and the transportation of unit loads on lot sizing. $\mathrm{Ng}$ et al. [20] studied a type of $E O Q$ problem where the (maximum) warehouse capacity is a decision variable. Furthermore, they assumed that the warehouse cost dominates all the other inventory holding costs. Keskin et al. [21] study generalized vendor selection models aimed at optimizing the total logistical costs including not only the vendor-specific fixed management and purchasing costs considered in traditional models, but also the transportation, inventory replenishment, and holding costs. 
In their models, the authors mainly used convex optimization as a mathematical tool. However, dynamic models for EOQ have been less considered. To fulfill this gape, we formulate in this paper EOQ model as a calculus of variations. The new problem is a simple optimal control which can be solved by Euler-Lagrange equation as optimality conditions. In particular, we obtain the well-known EOQ formula [1].

\section{Calculus Variations Approach to EOQ}

Assume that holding cost per unit depends on its rate and quantity of items.

In other words,

$$
C=C\left(q, q^{\prime}, t\right)
$$

where $C: R \times R \times R \rightarrow R, q: R \rightarrow R, q=q(t), C$ is the cost function at moment $t$ per each inventory. And $q$ is the quantity inventory.

Then total cost is

$$
T C=\int_{0}^{T} C\left(q, q^{\prime}, t\right) q(t) \mathrm{d} t .
$$

Economic order quantity problem can be formulated as a problem of calculus of variations with a free left side constraint $q_{0}$.

$$
\left\{\begin{array}{l}
\min \int_{0}^{T} F\left(q, q^{\prime}, t\right) \mathrm{d} t \\
q(0)=q_{0} \\
q(T)=0
\end{array}\right.
$$

where, $q(t)$ : order quantity function, $q_{0}$ : economic order quantity, $T$ : final time, $F\left(q, q^{\prime}, t\right)=C\left(q, q^{\prime}, t\right) q(t)$.

In order to solve problem (2), we need to solve Euler-Lagrange equation [22] as an optimality condition for the calculus of variations.

$$
\frac{\partial F\left(q, q^{\prime}, t\right)}{\partial q}-\frac{\mathrm{d}}{\mathrm{d} t}\left(\frac{\partial F\left(q, q^{\prime}, t\right)}{\partial q^{\prime}}\right)=0
$$

Let $q^{*}=q^{*}\left(c_{1}, c_{2}, t\right)$ be a solution to problem (3). The constants $c_{1}$ and $c_{2}$ can be found from the boundary conditions [15] solving a system of nonlinear equations.

$$
\left\{\begin{array}{l}
\frac{\partial F\left(q^{*}, q^{*^{\prime}}, 0\right)}{\partial q^{*}}=0 \\
q^{*}(T)=0
\end{array}\right.
$$

For example, if we have $F\left(q, q^{\prime}, t\right)=12 q t+q q^{\prime}+q^{\prime 2}, q(0)=q_{0}$ and $q(1)=0$, then Euler-Lagrange equation is:

$$
12 t+q^{\prime}-q^{\prime}-2 q^{\prime \prime}=0 .
$$

The solution is $q\left(t, c_{1}, c_{2}\right)=t^{3}+c_{1} t+c_{2}$.

Clearly, $q(0)=c_{2}=q_{0}$, and the system (4) gives 


$$
\left\{\begin{array}{l}
\frac{\partial F}{\partial q^{\prime}}=q+2 q^{\prime}=\left(t^{3}+c_{1} t+c_{2}\right)+\left.2\left(3 t^{2}+c_{1}\right)\right|_{t=0}=c_{2}+2 c_{1} \\
q(T)=T^{3}+c_{1} T+c_{2}
\end{array}\right.
$$

Now we have condition (4) as

$$
\left\{\begin{array}{l}
c_{2}+2 c_{1}=0 \\
T^{3}+c_{1} T+c_{2}=0
\end{array}\right.
$$

Hence, we have $c_{1}=\frac{T^{3}}{2-T}$ and $c_{2}=\frac{2 T^{3}}{T-2}$, consequently, $q_{0}=\frac{2 T^{3}}{T-2}$. Then optimal solution is

$$
q^{*}(t)=t^{3}+\frac{T^{3}}{2-T} t+\frac{2 T^{3}}{T-2}:
$$

In practice, usually type of order quantity function is given. For instance,

$q(T)=b T+d$, and holding cost per unit is constant $c_{h}$. Then total cost minimum problem is:

$$
\left\{\begin{array}{l}
\min T C=\frac{D c}{q_{0}}+\int_{0}^{T}(b t+d) c_{h} \mathrm{~d} t \\
q(0)=d=q_{0}^{\prime} \\
q(t)=b T+d=0,
\end{array}\right.
$$

where, $D$ is demand for the period $T$, and $c$ ordering cost. $b$ can be expressed as

$$
b=-\frac{d}{T}=-\frac{q_{0}}{T} .
$$

Then the cost function $T C$ has the form.

$$
\min T C=\frac{D C}{q_{0}}+\int_{0}^{T}\left(-\frac{q_{0}}{T} t+q_{0}\right) c_{h} \mathrm{~d} t
$$

or equivalently,

$$
T C=\frac{D c}{q_{0}}-\frac{q_{0} c_{h} T}{2}+q_{0} c_{h} T .
$$

Taking derivative of $T C$, we have

$$
\frac{\mathrm{d} T C}{\mathrm{~d} q_{0}}=-\frac{D C}{q_{0}^{2}}-\frac{c_{h} T}{2}+q c_{h} T=0 .
$$

Now we obtain

$$
\frac{D c}{q_{0}^{2}}=\frac{c_{h} T}{2} .
$$

We find optimal order quantity $q_{0}$ as

$$
q_{0}=\sqrt{\frac{2 D c}{c_{h} T}} .
$$

If we take $T=1$, then we have well known economic order quantity formula $(E O Q)$ in the literature [1]. 


$$
q_{0}=\sqrt{\frac{2 D c}{c_{h}}} .
$$

\section{Conclusion}

An extended $E O Q$ model has been considered for the first time as a simple optimal control problem with an unknown initial state. In particular, from the proposed model we obtain the well-known $E O Q$ formula. The proposed approach allows to examine the order quantity function from a view point of dynamic system. That is why the stock can be controlled at each action time. The model was tested on a numerical example.

\section{Acknowledgements}

This work was supported by the research grants P2017-2373 of National University of Mongolia.

\section{References}

[1] Drake, M.J. and Marley, K.A. (2014) A Century of the EOQ. In: Tsan-Ming, C., Ed., Handbook of EOQ Inventory problems, Springer, New York, 3-22. https://doi.org/10.1007/978-1-4614-7639-9_1

[2] Axsäter, S. (1996) Using the Deterministic EOQ Formula in Stochastic Inventory Control. Management Science, 42, 830-834. https://doi.org/10.1287/mnsc.42.6.830

[3] Huang, W., Kulkarni, V.G. and Swaminathan, J.M. (2003) Optimal EOQ for Announced Price Increases in Infinite Horizon. Operations Research, 51, 336-339. https://doi.org/10.1287/opre.51.2.336.12785

[4] Khan, M., Jaber, M.Y., Guiffrida, A.L. and Zolfaghari, S. (2011) A Review of the Extensions of a Modified EOQ Model for Imperfect Quality Items. International Journal of Production Economics, 132, 1-12. https://doi.org/10.1016/j.ijpe.2011.03.009

[5] Pentico, D.W. and Drake, M.J. (2011) A Survey of Deterministic Models for the EOQ and EPQ with Partial Backordering. European Journal of Operational Research, 214, 179-198. https://doi.org/10.1016/j.ejor.2011.01.048

[6] Rao, S.S. and Bahari-Kashani, H. (1990) Economic Order Quantity and Storage SizeSome Considerations. Engineering Costs and Production Economics, 19, 201-204. https://doi.org/10.1016/0167-188X(90)90043-H

[7] Zhang, R.-Q., Kaku, I. and Xiao, Y.-Y. (2011) Deterministic EOQ with Partial Backordering and Correlated Demand Caused by Cross-Selling. European Journal of Operational Research, 210, 537-551. https://doi.org/10.1016/j.ejor.2010.10.001

[8] Brill, P.H. and Chaouch, B.A. (1995) An EOQ Model with Random Variations in Demand. Management Science, 41, 937-936. https://doi.org/10.1287/mnsc.41.5.927

[9] Choi, H., Malstrom, E.M. and Classen, R.J. (1984) Computer Simulation of Lot-Sizing Algorithms in Three-Stage Multi-Echelon Inventory Systems. Journal of Operations Management, 4, 259-277. https://doi.org/10.1016/0272-6963(84)90015-9

[10] Evan, L.P. (1986) Optimal Lot Sizing, Process Quality Improvement and Setup Cost Reduction. Operations Research, 34, 137-144. https://doi.org/10.1287/opre.34.1.137

[11] Melnyk, S.A. and Piper, C.J. (1985) Leadtime Errors in MRP: The Lot-Sizing Effect. International Journal, 23, 253-264. https://doi.org/10.1080/00207548508904706 
[12] Bassin, W. (1990) A Technique for Applying EOQ Models to Retail Cycle Stock Inventories. Journal of Small Business Management, 28, 48-55.

[13] Lev, B. and Weiss, H.J. (1990) Inventory Models with Cost Changes. Operations Research, 38, 53-63. https://doi.org/10.1287/opre.38.1.53

[14] Chyr, F., Tsong, M.L. and Chin-Fu, H. (1990) An Extension of the EOQ Production Model Based on Damage Costs. International Journal of Operations and Production Management, 10, 71-76. https://doi.org/10.1108/01443579010006406

[15] Toews, C., Pentico, D.W. and Drake, M.J. (2011) The Deterministic EOQ and EPQ with Partial Backordering at a Rate That Is Linearly Dependent on the Time to Delivery. International Journal of Production Economics, 131, 643-649. https://doi.org/10.1016/j.ijpe.2011.02.007

[16] Chung, K.-J. and Cardenas-Barrón, L.E. (2012) The Complete Solution Procedure for the EOQ and EPQ Inventory Models with Linear and Fixed Backorder Costs. Mathematical and Computer Modelling, 55, 2151-2156. https://doi.org/10.1016/j.mcm.2011.12.051

[17] Taleizadeh, A.A., Pentico, D.W., Jabalameli, M.S. and Aryanezhad, M. (2013) An EOQ Model with Partial Delayed Payment and Partial Backordering. Omega, 41, 354-368. https://doi.org/10.1016/j.omega.2012.03.008

[18] Eppen, G. (1979) Effects of Centralization on Expected Costs in a Multi-Location Newsboy Problem. Management Science, 25, 498-501. https://doi.org/10.1287/mnsc.25.5.498

[19] Tanchoco, J.M.A., Davis, R.P. and Wysk, R.A. (1980) Economic Order Quantities Based on Unit-Load and Material Handling Considerations. Decision Sciences, 11, 514-521. https://doi.org/10.1111/j.1540-5915.1980.tb01156.x

[20] Ng, C.T., Chenga, T.C.E., Kotov, V. and Kovalyov, M. (2009) The EOQ Problem with Decidable Warehouse Capacity: Analysis, Solution Approaches and Applications. Discrete Applied Mathematics, 157, 1806-1824. https://doi.org/10.1016/j.dam.2009.01.004

[21] Keskin, B.B.H. and Üster, S.Ç. (2010) Integration of Strategic and Tactical Decisions for Vendor Selection under Capacity Constraints. Computers and Operations Research, 37, 2182-2191. https://doi.org/10.1016/j.cor.2010.03.008

[22] Enkhbat, R. (2006) Optimization-2 (Calculus of Variations with Economic Applications). NUM Press, Ulaanbaatar. 